\title{
Developing Intellectual Capital in Professional Service Firms Using High Performance Work Practices as Toolkit
}

\author{
Junaid Rehman \\ University of Technology, Sydney \\ junaid.rehman@student.uts.edu.au \\ Osama Sohaib \\ University of Technology, Sydney \\ osama.sohaib@uts.edu.au
}

\author{
Igor Hawryszkiewycz \\ University of Technology, Sydney \\ igor.hawryszkiewycz@uts.edu.au \\ Altaf Mazhar Soomro \\ University of Technology, Sydney \\ altaf.m.soomro@student.uts.edu.au
}

\begin{abstract}
The role of Professional Service Firms (PSFs) has always been crucial in the development of knowledge economies. The effectiveness of these firms is highly attributed to the knowledge capabilities and skills embedded in its human resources and how effectively these resources are utilized in the optimal benefit of the firm. Owing to the ever-increasing growth of the services sector globally, it's critical for the PSFs to gain in-depth awareness on the application of HighPerformance-Work-Practices (HPWPs) so as to continually maintain quality of their services to the clients. However, the mechanism for systematically designing and implementing these practices in intellectual capital context is still not fully developed. This research, therefore, theoretically investigates and suggests a linkage mechanism on how Strategic HRM Practices (HPWPs) via (Ability, Motivation and Opportunity)-enhancing bundles stimulate intellectual capital development in professional service firms. By presenting a conceptual framework, this study offers practically meaningful insights to the managers in the service firms on how to implement these practices for effectively meeting client needs and sustaining a competitive advantage.
\end{abstract}

\section{Introduction}

HRM scholars and practitioners argue that competent workforce contributes to firm performance and industry competitiveness because of the knowledge and competencies acquired by them as a result of firm's intellectual capital development [54]. This viewpoint gave rise to the growth of Strategic Human Resource Management (SHRM). In views of Fareed et al. [15], skilled and competent human resource helps organizations successfully compete in the business environment. Consistent with the Resource-BasedView (RBV), quality human resource is central to the growth \& development of robust human capital, leading to a sustained competitiveness of the firm [5]. Marimuthu et al. [41] emphasized that successful organizations craft strategies that not only help them build their human capabilities but also support the achievement of business goals through improved productivity and efficiency. However, achieving this requires firms to capitalize on the employees, ensuring that they are equipped with the required set of capabilities and skills to perform their jobs effectively. Although, both tangible \& intangible assets are needed by the organizations to demonstrate and successfully develop competitive strategies, however, today knowledge-based economies are focusing more on intellectual capital as critical for strategic management of organizational knowledge in order to survive in a complex business environment [4]. Intellectual capital, when viewed from SHRM perspective, focuses on realigning the human knowledge and intellectual assets of a firm in line with its core strategies.

We draw upon SHRM and IC literature that guides the creation of conceptual research framework and aids in in theoretical investigation of the underlying research question - 'How AMO bundles of HPWP Support Intellectual Capital Development in the Professional Service Firms?'. That's to say - how HPWPs impact the intellectual capital bottom-line in Professional Service Firms (PSFs)?

The remainder of this paper is organized as follow. Section-2 gives a considerable account of literature review followed by Section-3 that presents a conceptual research framework and consequently supporting research hypotheses. Section-4 sums up and 
concludes the discussion, highlighting implications of the theoretical enquiry. Finally, Section-5 envisages future research plan and direction for empirically validating the conceptual framework through application of appropriate research methods.

\section{Theoretical Background}

\subsection{High Performance Work Practices (HPWPs)}

In the extant literature, HPWPs have been identified by varying names such as Strategic Human Resource Management Practices, High Performance Work System, High Commitment Management etc. [15, 3]. HPWPs refer to a set of practices involving a blend of self-managed work teams and socio-technical systems [65]. In the eyes of Nadler et al. [44], HPWPs constitute a cluster of people, work processes, technologies and information synergized in a manner to reap optimum benefit from their combination. HPWPs usually involve comprehensive staffing policies, employee performance management mechanisms, rewards \& recognition system, training \& continuous development etc. Each of these is aimed at building and enhancing employee skills and attitude needed to effectively execute firm's core strategies [15, 29]. Appelbaum et al. [2] consider HPWPs as modern employee development initiative such as self-directed teams, employee trainings, performance-based pay, job security, reduced status distinction etc. Zacharatos et al. [69] determined various HPWPs such as effective teams, contingent reward policy, selective hiring, decentralized decision making, transformational leadership, information-sharing etc. [16].

Although, the modern information-sharing tools, communication systems and collaborative technologies support organizational work activities, nevertheless, these technological capabilities would not effectively serve the purpose if the staff is not adequately skilled and motivated to adopt them $[16,43]$. This is because of the indispensible role of organizational human resource towards persistently achieving corporate goals. Hence, there is a broad consensus that managers can enhance employee performance and creativity at the workplace by motivating them to take discretionary efforts and participate in the decision making [2]. This managerial approach enhances employees' flexibility, competency and engagement and plays a pivotal role in deriving organizational performance $[14,29]$.

Hence, consistent with the objectives of this research and considering the underlying research question, we have identified certain number of HPWPs. The rationale behind their selection and methodological choice is discussed in Section 3 of this paper. As a whole, successful application of suggested practices would help achieve IC development goals in the service firms.

2.1.1. AMO Model/Bundle Perspective in HPWPs. In the SHRM literature, there is broad agreement that the effect of bundles of HPWPs on firm effectiveness is far more than the individually applied practices [68]. To this end, Appelbaum et al. [2] underscored that a blend of three bundles of HRM practices constitute a holistic system of HPWPs. They termed these bundles as: Ability-enhancing practices (such as training, learning opportunities etc) - A; Motivation-enhancing practices (e.g. employee autonomy, reward based on performance, merit-based promotions etc.) - $\mathbf{M}$; and the Opportunity-enhancing practices that provide employees an opportunity to fully utilize their skills (such as employee communications, sharing key information with the employees, grievance procedure etc.) - O. The AMO model serves as an effective framework for categorizing and understanding the significance of individual practices. According to Appelbaum et al. [2], an appropriate mix of AMO components spurs employee performance and creativity. A tactful combination of three bundles of practices promotes employee satisfaction and commitment to work which translates into higher performance and productivity at the workplace [61, 32].

2.1.2. HPWPs in Professional Service Firms (PSFs). The effect of HPWPs on firm performance in the context of the large firms is quite evident in the extant literature such as [61], [43], [29] etc. to name a few. However, according to Fu et al. 2017 [19], the research on the implementation of HPWP in Professional Service Firms (PSFs) is reasonably insufficient and still in its early stages except the studies like [15], [17] and [42]. Most of the research has predominately covered manufacturing and routinized firms. Hence, PSFs offer an important context for investigating the effects of HPWPs on the organizational intellectual capital as the success of these firms is largely reliant on the skill and capabilities of their staff [19].

In general, Professional Service Firms are characterized by the virtue of their niche way of offering customized and specialized services to the clients and hence rely on the idiosyncratic skills and problem-solving abilities of their professional staff [19]. By applying their knowledge and expertise, staff members not only contribute to organizational knowledge base but also help build client relationships [74]. This ability to derive knowledge-based competitive advantage serves as the most critical factor towards the success of these firms, making our 
investigations of IC phenomena highly relevant in the context of service firms.

\subsection{Intellectual Capital (IC)}

Intellectual Capital (IC) refers to a cumulative sum of organizational resources comprising of its knowledge, skills, competencies, experience and intellectual property that collectively add value to an organization [8, 51, 58]. IC facilitates competitive market positioning of a firm particularly when its physical assets are no longer able to achieve sustainable advantage. This is because IC capabilities are unique \& non-substitutable and vary from firm to firm, so the investment in IC depends on the type of the firm [35]. An organization attains optimum IC potential when it acquires intellectual capabilities comprising of human capabilities, work processes, structural capabilities and organizational culture [31]. Various scholars have worked on IC dimensions. Subramaniam \& Youndt [59] proposed human, organizational \& social capital as IC dimensions. However, the researchers such as Bontis [8], Roos et al. [51] and Stewart [58] proposed Human, Structural \& Relational capital as IC dimensions. These dimensions are also in coherence with the dimensions suggested by the Meritum Project (European Universities Consortium). Following the broad consensus, this research would take into account the dimensions proposed by the later scholars.

Human Capital. It incorporates tacit knowledge, skills, experience, competencies, talents, and innovativeness of organizational human resources [51]. An organization can't own human capital but it can only be hired and the organization is created by its individuals, not the organization itself [58, 45]. According to Grasenick \& Low [20], new employees possess human capital when they become part of an organization thereby contributing to the organizational memory and vice versa case when they leave the organization. This is owing to the fact that talent, skills and tacit knowledge of the individuals are not retained when they are no more part of the organization $[8,51]$. This makes human capital the most important intellectual capital dimension [13].

Structural Capital. Also labeled in literature as organizational capital, it represents supportive infrastructure, systems and physical assets that facilitate knowledge, learning and routine work activities in an organization [13]. It is basically a sum total of knowledge capabilities that are retained by an organization even after its members have left the organization $[20,51]$. Some common examples include organizational information systems, automation tools, knowledge databases, organizational work culture, routine processes, management capabilities, intellectual property and anything that results in value creation for the organization [35]. For an organization, structural capital facilitates the development of infrastructures and mechanisms to assist individuals to make the most of their intellectual capabilities, leading to improved organizational performance [9].

Relational Capital. Termed additionally as customer capital sometimes, it refers to the relationship maintained by an organization with its externalstakeholders and the opinion held by them about the organization coupled with communication and exchange of knowledge between both the parties [9]. In particular, it involves customer loyalty and goodwill, mutual trust, business collaboration and long-term relationships of the firm with its suppliers and partners, understanding of legal matters, knowledge of regulatory issues, competitors' intelligence etc [35].

\subsection{HPWPs and Intellectual Capital Development}

Literature acknowledges that HPWPs serve as the working mechanism for promoting human capital of an organization [13]. It has been recognized that HPWPs stimulate employee performance and creative thinking by enhancing their key competencies such as knowledge, skills and abilities. Firms implement these practices in bundles with an aim to hire, train, develop and retain their employees. These elements are hard to imitate by the opponents owing to the strategic nature of HPWPs implementation [43, 32]. Although, the role of HPWPs in achieving performance outcomes has been phenomenal, nonetheless, researchers argue that the linking mechanism between these practices and intellectual capital development is still less explored [30]. As mentioned earlier, IC clearly combines organizational knowledge in three interrelated components i.e. human, structural \& relational capitals [51], these components offer a well-structured framework for effectively applying the strategic HRM practices [15]. Accordingly, these practices, when integrated into organizational thinking promote all IC dimensions, leading to overall growth of the intellectual capital [68].

2.3.1. HPWPs and Human-Capital Development. An organization's human capital resides in the heads of the employees as tacit knowledge \& skills which are inculcated via a series of HRM initiatives, for instance, employee hiring, placement, training, capacity building etc [13]. The pool of human capital resources grows when an organization inducts new staff members. However, the human capital embedded in the newlyinducted staff is not aligned according to the firm 
requirements [20]. To this end, Hatch \& Dyer [24] argued that the human resource acquired by an organization must go through organizational adjustments before their abilities could be optimally reaped to best meet the needs of the new environment. They further highlighted that the previous experience of new employees might also impact their abilities, restricting the 'unlearn' \& 're-learn' of knowledge at new workplace. This implies that human capital transitioning through individual movement from one organization to another is not as easy as perceived. Thus, organizations need to concentrate more on developing and nurturing their human capital as mere recruitment of human resource wouldn't serve the purpose of gaining competitive edge [35].

\subsubsection{HPWPs and Structural-Capital Development.} The role of HPWPs is also critical towards the growth and development of structural capital. Hatch \& Dyer [24] claim that employee learning activities within a firm support the creation of firm-specific human capabilities which are hard to imitate by the competitors as they are unique and exclusive to the firm [25]. Other key components of structural capital, for example, organizational work culture, routines and innovative capabilities also help enhance human capabilities and maintain inimitability of the firm. Thus, HR managers, in addition to human capital, should also take into account the structural capital of their firms while designing and implementing HR strategies [35].

2.3.3. HPWPs and Relational-Capital Development. An organization can't work in the state of isolation, it often has to interact with the external stakeholders such as clients, customers, suppliers, partners etc [34]. Relational capital represents how an organization interacts with external agents by utilizing its in-house human and structural capitals to create sustainable value advantage [35]. Relational capital in fact helps an organization know more about the dynamics of external knowledge embedded in the stakeholder relationships. Through effective implementation of HPWPs, organizational human-capital assets can be nurtured to boost the overall human resource quality and effectiveness [36]. This high-quality human resource can potentially play a vital role in creating external knowledge and enhancing network of relationship with the external stakeholders [34]. The improved external network and stakeholder intelligence could be applied by a firm to revisit its strategic priorities in the given context. Relational capital, therefore, can be thought of as prime-mover of strategic innovation.

\subsection{Resource Based View (RBV) - An Underlying Linkage Mechanism}

The RBV of a firm expounds that it is fundamental for an organization to possess valuable resources and these must be unique, inimitable, non-substitutable and exceptional to the firm to create sustainable value for the organization $[6,66]$. RBV further states that it is prime responsibility of HR management to ensure achievement of corporate objectives through its human resources, having a potential to contribute towards the organizational goals. Employees in an organization possess varying level of competencies and motivation, which when utilized effectively, can result in long-term competitiveness of the firm [23].

Accordingly, a firm must invest in its employees by imparting training and developing their core skills, supporting them to accomplish their tasks effectively, resulting in value-added competitive advantage [54]. It is challenging to frequently replace employees as not all of them enjoy same level expertise and adaptability to adjust in a complex environment and add value to the firm [11]. Consequently, the contribution of RBV to organizational behavior literature has been enormous in terms of its theoretical expansion, empirical research and managerial practice.

\section{Research Conceptual Model and Hypotheses}

\subsection{Research Conceptual Model}

Extant literature on HPWPs highlights a large number of HPWPs. These practices have been evolving from time to time and their application varies from one culture to another [48]. Usually, business firms choose a number of these practices that fit their organizational culture and keeping in view the strategic performance outcomes they intend to drive e.g. firm performance, innovation capabilities, business system success etc. to name a few. As mentioned earlier that the effect of HPWPs when applied in bundles is far more than the individually applied practices [68]. Hence as part of this research, a number of practices were identified after extensive review of literature. We, however, limited their number to eight and each of these demonstrates a potential to influence the intellectual capital in service firms. We categorized these in three bundles i.e. Ability, Motivation and Opportunity (AMO). Some of these are commonly applied practices (such as Employee Empowerment, Training \& Development, Performance Based Reward) while others are relatively new (such as Knowledge Sharing, Shared Leadership, Teamwork Quality and Interpersonal Trust) and hence necessitate additional 
empirical validation [48]. Although, HPWPs are primarily applied by HR department on the employees as an organizational initiative, yet there are some practices whose effective application is more dependent on employee voluntary behavior [67], for example, Employee Knowledge Sharing and Interpersonal Trust in this case. Accordingly, a brief explanation of these practices within AMO bundles is given in the subsequent section.

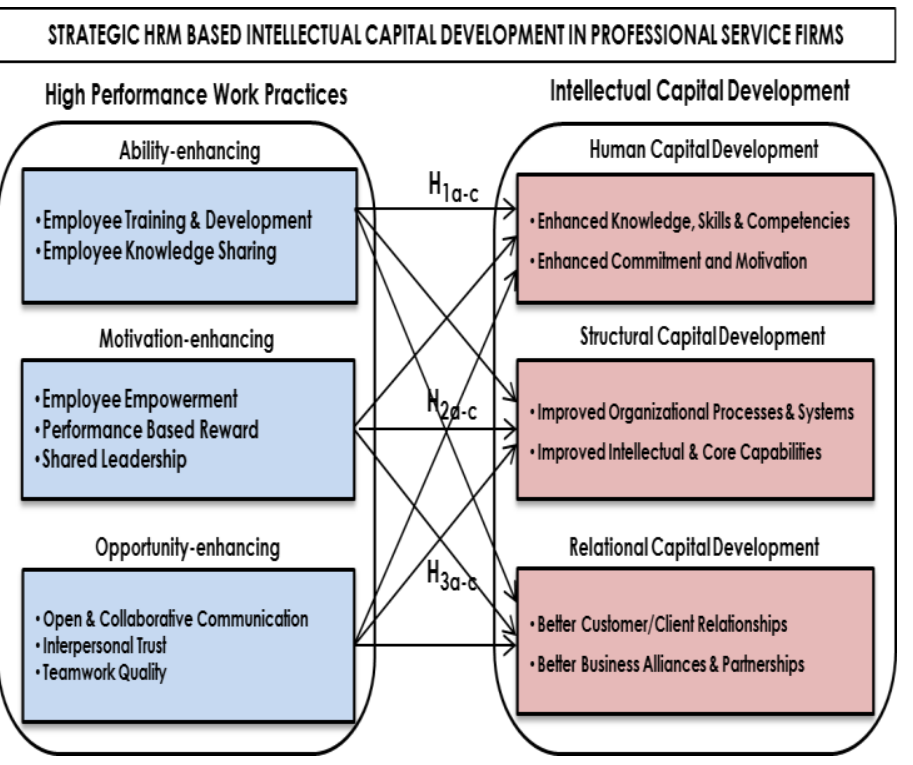

Figure1. Research Conceptual Model

\subsection{Research Hypotheses}

The primary aim of this research is to investigate the effect of (Ability, Motivation \& Opportunity)enhancing bundles of HPWPs on intellectual capital development. A brief explanation of each work practice within its corresponding bundle is given in the IC context of the firms followed by relevant hypothesis.

\subsubsection{Ability-enhancing HPWPs \& Intellectual} Capital. The most relevant HPWPs that we suggest within ability-enhancing category having a potential to promote intellectual capital in PSFs include: Employee Training \& Development and Employee Knowledge Sharing.

- Employee Training \& Development. In organizational context, the term training \& development is frequently used that refers to organizational initiative towards enhancing employee learning with an aim to achieve better performance [50]. As stated by Barlett [7], training is a planned managerial effort that results in a desired set of shared behaviors and motivations. It involves the concept of paying for knowledge that rewards employees for the competencies gained and applied at the workplace [63]. Researchers argue organizational performance improvement and knowledge effectiveness as the justifications behind imparting trainings [7]. Employee trainings contribute to development of their core skills and capabilities that consequently add to organizational knowledge and intellectual development [53].

- Employee Knowledge Sharing. A voluntary behavior of an individual that enables exchange of knowledge (explicit or tacit), ideas, information and experiences with another individual or group of people is referred to as knowledge sharing [46]. However, ensuring smooth sharing of knowledge is not easy as it necessitates strong willingness to collaborate with the others [39]. To facilitate knowledge flow among the employees, organizations need to ensure that employees feel morally obligated to share their knowledge $[17,1]$. Welch \& Welch [64] argued that the employees receiving knowledge from their colleagues are naturally motivated to reciprocate sharing of knowledge. Employees mostly share knowledge with individuals they are familiar with and consider trustworthy. In the IC development context, knowledge enablement between the employees reaps multitude of benefits to an organization such as creation of new knowledge, building competencies, solution to complex problems, generation of new ideas, fostering creativity, understanding customer needs etc. [46, 45].

Accordingly, it can be hypothesized within Abilityenhancing HPWPs that:

H1: Ability-enhancing HPWPs positively influence Intellectual Capital in Professional Service Firms (PSFs).

Hla: Ability-enhancing HPWPs positively influence human capital in PSFs.

H1b: Ability-enhancing HPWPs positively influence structural capital in PSFs.

H1c: Ability-enhancing HPWPs positively influence relational capital in PSFs.

3.2.2. Motivation-enhancing HPWPs and Intellectual Capital. The most relevant HPWPs suggested within Motivation-enhancing category include: Employee Empowerment, Performance Based Reward \& Shared Leadership. These are briefly described in the IC context here:

- Employee Empowerment. It refers to degree of autonomy given by the managers to their employees. Primarily, it defines the level of discretion or authority that can be exercised by the employees in relation to their routine roles and responsibilities 
[63]. Employee empowerment practices involve enabling decision making processes at various levels of an organization in line with its set goals [50]. The underlying assumption behind empowerment process is to delegate decision making authority to the employees in an effort to keep employees motivated and enhance performance [63]. Employee empowerment plays a pivotal role in achieving employee outcomes like job satisfaction and engagement which in turn serve as the basis for retaining the skilled human resources and hence maintaining the human capital of the firm.

- Performance Based Reward. Rewarding highperforming employees is considered an important managerial strategy toward influencing individual behavior and work related performance [47]. Reward system is usually extrinsic \& intrinsic in nature. Extrinsic rewards are more tangible in nature and given to the employees in recognition of their outstanding performance which may include higher pay, bonuses, extra incentives, promotions etc. However, not all employees can be motivated through monetary rewards. They also expect intrinsic rewards which they may receive in the form of better working conditions, job satisfaction etc [52]. The intrinsic rewards, however, are less tangible and more subjective as they create employee perception on the value of their job [47]. Performance rewards, if initiated properly, could be instrumental in building and enhancing organizational knowledge by keeping staff motivated [47].

- Shared Leadership. Shared leadership is a collaborative and dynamic process spread across organizational members and teams wherein leadership emerges from the teams and members lead each other to accomplish set goals [55]. Although, the process involves informal team processes occurring in parallel within the teams, it doesn't eliminate vertical leadership concepts. This perception of leadership necessitates shared responsibility and involvement of all team members in decision making process, enabling everyone to exercise leadership functions and act as a mentor within the team [26]. Based on individual's level of knowledge, competencies and nature of task, leadership role changes within the team [55]. As a whole, it offers an environment wherein all team member exercise leadership behavior and collaborative decision making which consequently leads to improved organizational knowledge outcomes [12].

Therefore, we may hypothesize within Motivationenhancing HPWPs that:
H2: Motivation-enhancing HPWPs positively influence Intellectual Capital in Professional Service Firms (PSFs).

H2a: Motivation-enhancing HPWPs positively influence the human capital in PSFs.

H2b: Motivation-enhancing HPWPs positively influence the structural capital in PSFs.

H2c: Motivation-enhancing HPWPs positively influence the relational capital in PSFs.

3.2.3. Opportunity-enhancing HPWPs and Intellectual Capital. The most relevant HPWPs that can be drawn within this category are: Open \& Collaborative Communication, Interpersonal Trust and Teamwork Quality. These are briefly described in IC context below:

- Open \& Collaborative Communication. Open communication facilitates transfer of tacit knowledge among the organizational members. Organizations embracing norms of open communication often manage to effectively overcome the barriers to knowledge exchange by motivating their employees to share their feelings and experiences [62]. The more employees interact and collaborate with each other, the more they share their inner thoughts [1]. Hence, in order to enhance organizational intellectual assets, employees should be encouraged to freely collaborate and speak their mind through sustained communications [37].

- Interpersonal Trust. According to Mäki 2015 [40], organizational members participate in communication and knowledge sharing activities based on the level of trust that exists between them. A trusting relationship is crucial to exchange of knowledge, mutual cooperation and interactions among the individual [1]. In the absence of feelings of trust, employees don't feel obligated to interact and share their knowledge [64, 40]. Interpersonal trust culture serves as a key constituent in a competitive business environment as it motivates individuals to voluntarily and willingly collaborate. This aspect makes it indispensible for organizational knowledge growth.

- Teamwork Quality. One of the key elements contributing towards effective high-performing teams is teamwork. Success of a team is based on how interactive the communications between the team members are [10]. To further enhance the effectiveness, Hoegl and Gemuenden [27] added qualitative aspect in the notion of teamwork by introducing the concept of Teamwork Quality (TWQ). According to them, TWQ describes quality of interaction among the team members achieved via better coordination, collaborations, mutual harmony and cohesion. These quality attributes could serve as 
key ingredients towards organizational intellectual effectiveness.

Hence, we may hypothesize within Opportunityenhancing HPWPs that:

H3: Opportunity-enhancing HPWPs positively influence the Intellectual Capital in Professional Service Firms (PSFs).

H3a: Opportunity-enhancing HPWPs positively influence the human capital in PSFs.

H3b: Opportunity-enhancing HPWPs positively influence the structural capital in PSFs.

H3c: Opportunity-enhancing HPWPs positively influence the relational capital in PSFs.

\section{Discussion and Conclusion}

This paper was aimed at theoretically exploring the effectiveness of HPWPs as a toolkit for intellectual capital development in the service firms. By highlighting the effectiveness of high performance work practices in building and enhancing intellectual capital in the service firms, this study not only contributes to the strategic HRM literature in general but also augments the perspective of Resource Based View theory. The findings of this theoretical enquiry are also consistent with the previous studies such as Fareed et al. 2016 [73], Fu et al. 2017 [19], Messersmith et al. 2010 [43], Kamaluddin et al. 2016 [31] etc. The theoretical research enquiry overall argues that strategic HR practices nurture employee ability and creativity, resulting in the growth of intellectual knowledge capabilities of the firms. This is to say - the theoretical model emphasizes on the effectiveness of human resources as critical to sustaining a competitive advantage in the service firms. Practically speaking, it helps in determining how individual practices, when applied in bundles, stimulate various intellectual capital dimensions and which of these practices Professional Service Firms need to adopt, implement or sustain in order to further build their intellectual capabilities and resources. In addition, this research when empirically tested, would add new perspectives on intellectual capital development via a framework to guide HR executives on enhancing value and sustaining a competitive advantage over the rivals.

\subsection{Research Implications}

This research enquiry grounded on theoretical underpinnings offers remarkable theoretical contribution and an enormous potential to significantly contribute on a practical front upon empirical testing of the theoretical framework. In view of its significant implications for both researchers and HRD practitioners, it offers a theoretical framework to understand the nexus between HPWPs and intellectual capital development in the context of service firms.

Managerially speaking, it suggests HR managers to undertake an active and vibrant role in critically and meaningfully exploring organizational work practices and intellectual capabilities embedded in the employees and organizational systems as this aspect is often under-utilized in the service firms. Hence, it provides HR practitioners a configuration of HPWP bundles having a potential to support the growth of intellectual capital. By understanding the effect that HPWPs have on intellectual capital development, managers should be able to accurately measure both intangible and tangible assets of their firms which would consequently enable them to revisit strategic priorities on further enhancing their organizational knowledge and intellectual bottom-line in the form of enhanced employee skills, improved organizational systems and better customer relationships.

\section{Future Research Plan and Direction}

Prior research on HPWPs is mostly quantitative in nature with an exception of the work of some scholars like Özçelika [70] and Tregaskis [61] who adopted mixed methodology in their research. In view of these gaps and considering the inadequate research done on HPWPs in the context of Professional Service Firms (PSFs) [18, 19, 42], we aim to empirically test our theoretical framework in PSFs through the application of mixed methods. A combination of methods would help understand the problem context from both quantitative and qualitative lenses, thereby methodologically enriching the research literature [72].

The quantitative enquiry via online surveys would enable testing of the hypotheses and empirical validation of the proposed research model, whereas the qualitative examination via face-face interviews would assist in cross-validation of the findings from the quantitative enquiry $[49,71,72]$. As a whole, a blend of both quantitative and qualitative methods would not only aid in corroborating the quantitative findings but also offer comprehensive insights and rich mix of findings governing the relationship between HPWPs and IC development in the context of service firms.

Last but not the least, in view of the application of above research methods, the theoretical framework to be empirically-tested would resultantly lead to more meaningful insights and practical set of recommendations for scholars in general and $\mathrm{HR}$ managers responsible for training, knowledge 
management and capacity building of the employees in the professional service firms in particular.

\section{References}

[1] Al-Alawi, A.I., Al-Marzooqi, N.Y., Mohammed, Y.F. "Organizational Culture and Knowledge Sharing: Critical Success Factors." Journal of Knowledge Management. vol, 11, no 2, pp. 22-42, 2007.

[2] Appelbaum, E., Bailey, T., Berg, P., Kalleberg, A. L.

"Manufacturing Advantage: Why High Performance Work Systems Pay Off." Ithaca, NY: Cornell University Press, 2000.

[3] Arthur, J.B. "Effects of Human Resource Systems on Manufacturing Performance and Turnover." Academy of Management Journal, vol. 37, pp. 670-687, 1994.

[4] Aryee, S., Walumbwa, F.O., Seidu, E.Y., Otaye, L.E. "Developing and Leveraging Human Capital Resource to Promote Service Quality: Testing a Theory of Performance." Journal of Management. vol. 42, no. 2, pp. 480-499, 2016.

[5] Barney, J., "Firm Resources and Sustained Competitive Advantage." Journal of Management, vol. 17, no. 1, pp. 99120, 1991a.

[6] Barney, J., "The Resource-Based Model of the Firm: Origins, Implications, and Prospects." Journal of Management, vol. 17, no. 1, pp. 97-98, 1991b.

[7] Bartlett, K.R., "The Relationship Between Training and Organizational Commitment: A Study in the Health Care Field." Human Resource Development Quarterly. Vol. 12, pp. 335-353, 2001.

[8] Bontis, N., "Managing Organizational Knowledge by Diagnosing Intellectual Capital. In: Choo and Bontis, N. (eds.) The Strategic Management of Intellectual Capital and Organizational Knowledge," pp. 621-642. Oxford University Press, New York, 2002.

[9] Bontis, N., W, K., Richardson, S., "Intellectual Capital and Business Performance in Malaysian Industries." Journal of Intellectual Capital vol, 1, no.1, pp. 85-100, 2000.

[10] Budijanto, R.R., "Thinking Styles, Teamwork Quality and Performance," PhD Thesis. University of Canberra 2013.

[11] Cardy, R.L., Salvarajan, T. "Competencies: Alternative Frameworks for Competitive Advantage." Business Horizons, vol. 49, no. 3, pp. 235-245, 2006.

[12] Carson, J. B., Tesluk, P.E., Marrone, J.A., "Shared Leadership in Teams: An Investigation of Antecedent Conditions." Academy of Management Journal, vol. 50, no. 5, pp. 1217-1234, 2007.

[13] Chen, S., Wang, D. "Does Intellectual Capital Matter? High-Performance Work Systems and Bilateral Innovative Capabilities." International Journal of Manpower, vol. 34, no. 8, pp. 861-879, 2013.

[14] Combs, J., Liu, Y., Hall, A., Ketchen, D., "How Much Do High-Performance Work Practices Matter? A MetaAnalysis of Their Effects on Organizational
Performance." Personnel Psychology vol. 59, no. 3, pp. 501-528, 2006.

[15] Fareed, M., Isa, M.F.M., Noor, W.S., "HR Professionals' Effectiveness Through Human Capital Development, Organizational Culture and High Performance Work System: A Proposed Frame-work." International Business Management 10 (9), pp. 1720-1728, 2016.

[16] Fareed, M., Isa, M.F.M. and Noor, W.S., "Human Resource Professionals' Effectiveness, Organizational Culture and High Performance Work System Link: Evidence from Pakistan." International Review of Management and Marketing vol. 7, no. 1, pp. 85-94, 2017.

[17] Fathi, N.M., Eze, U.C., Goh, G.G., "Key Determinants of Knowledge Sharing in an Electronics Manufacturing Firm in Malaysia." Library Review vol. 60, pp. 53-67, 2011.

[18] Fu, N., Flood, P., Bosak, J., Morris, T., O’Regan, P., "How Do High Performance Work Systems Influence Organizational Innovation in Professional Service Firms?." Employee Relations: The International Journal, vol. 37, no. 2, pp. 209-231, 2015.

[19] Fu, N., Flood, P.C., Bosak, J., Rousseau, D.M., Morris, T., O'regan, P., "High-Performance Work Systems in Professional Service Firms: Examining the PracticesResources-Uses Performance Linkage.”, Human Resource Management vol. 56, no. 2, pp. 329-352, 2017.

[20] Grasenick, K., Low, J. "Shaken, Not Stirred: Defining and Connecting Indicators for the Measurement and Valuation of Intangibles." Journal of Intellectual Capital vol. 5, no. 2, pp. 268-281, 2004.

[21] Guthrie, J., Flood, P., Liu, W., MacCurtain, S. "High Performance Work Systems in Ireland: Human Resource and Organizational Outcomes." Internal Journal of HRM, vol. 20, pp. 112-125, 2009.

[22] Hair, F., Marko, J.S., Lucas, H., Volker, G.K., "Partial Least Squares Structural Equation Modeling (PLS-SEM): An Emerging Tool in Business Research." European Business Review, vol. 26, no. 2, pp. 106-121, 2014.

[23] Haslinda, A., "Evolution Terms of Human Resource Management and Development." The Journal of International Social Research, vol. 2, no. 9, pp. 180-186, 2009.

[24] Hatch, N.W., Dyer, J.H., "Human Capital and Learning As a Source of Sustainable Competitive Advantage." Strategic Management Journal, vol. 25, no. 12, pp. 11551178, 2004.

[25] Hitt, M.A., Bierman, L., Shimizu, K., Kochhar, R., "Direct and Moderating Effects of Human Capital on Strategy and Performance in Professional Service Firms: A Resource-Based Perspective." Academy of Management Journal, vol. 44, no. 1, pp. 13-28, 2001.

[26] Hoch, J.E., "Shared Leadership, Diversity, and Information Sharing in Teams." Journal of Managerial Psychology, vol. 29, no. 5, pp. 541-564, 2014.

[27] Hoegl, M., Gemuenden, H., "Teamwork Quality and the Success of Innovative Projects: A Theoretical Concept 
and Empirical Evidence." Organization Science, vol. 12, no. 4, pp. 435-449, 2001.

[28] Hsu, J.S., Li,Y., Sun,H. "Exploring the Interaction Between Vertical and Shared Leadership in Information Systems Development Projects." International Journal of Project Management, vol. 35, pp. 1557-1572, 2017.

[29] Huselid, M.A., "The Impact of Human Resource Management Practices on Turnover, Productivity, and Corporate Financial Performance." Academy of Management Journal, vol. 38, no. 3, pp. 635-672, 1995.

[30] Jiang, J.Y., Liu, C.W., "High Performance Work Systems and Organizational Effectiveness: The Mediating Role of Social Capital." Human Resource Management Review, vol. 25, pp. 126-137, 2015.

[31] Kamaluddin, A., Rahman, R.A.: Enhancing Organization Effectiveness Through Human, Relational and Structural Capital: An Empirical Analysis. Malaysian Acc Review 8(1), 1-17 (2016).

[32] Kehoe, R.R., Wright, P.M., "The Impact of HighPerformance Human Resource Practices on Employees' Attitudes and Behaviors." Journal of Management, vol. 39, pp. 366-391, 2013.

[33] Kianto, A., Sáenzb, J., Aramburub, N., "KnowledgeBased Human Resource Management Practices, Intellectual Capital and Innovation.' Journal of Business Research, vo. 81, pp. 11-20, 2017.

[34] Kong, E., "Facilitating Learning Through Intellectual Capital in Social Service Non-Profit Organizations." International Journal of Learning, vol. 16, no. 2, pp. 533550, 2009.

[35] Kong, E., Thomson, S.B., "An Intellectual Capital Perspective of Human Resource Strategies and Practices. Knowledge." Management Research \& Practice, vol. 7, pp. 356-364, 2009.

[36] Kucherov, D., Manokhina, D., "Evaluation of Training Programs in Russian Manufacturing Companies." European Journal of Training and Development, vol. 41, no. 2, 2017.

[37] Lawn, S., Delany, T., Sweet, L., Battersby, M. Skinner, T., "Barriers and Enablers to Good Communication and Information-Sharing Practices in Care Planning for Chronic Condition Management." Australian Journal of Primary Health, vol. 21, no. 1, 2015.

[38] Lepak, D.P., Snell, S.A., "Examining the Human Resource Architecture: The Relationships Among Human Capital, Employment, and Human Resource Configurations." Journal of Management, vol. 28, no. 4, pp. 517-543, 2002.

[39] Ling, T.N., San, L.Y., Hock, N.T., "Trust: Facilitator of Knowledge-Sharing Culture." Communications of the IBIMA, vol. 7, pp. 137-142, 2009.

[40] Mäki. A.R., "The Barriers of Knowledge Sharing in Multicultural Organization.” Master Thesis. University of Oulu, 2015.

[41] Marimuthu, M., Arokiasamy, L., Ismail, M., "Human Capital Development and Its Impact on Firm
Performance: Evidence From Developmental Economics" The Journal of International Social Research, vol, 2, no. 8, pp. 265-272, 2009.

[42] McClean, E., Collins, C.J., "High-Commitment HR Practices, Employee Effort, and Firm Performance: Investigating the Effects of HR Practices Across Employee Groups Within Professional Services Firms." Human Resource Management, vol. 50, no. 3, pp. 341363, 2011.

[43] Messersmith, J.G., Guthrie, J.P., "High Performance Work Systems in Emergent Organizations: Implications for Firm Performance." Human Resources Management vol. 49, no. 2, pp. 241-264, 2010.

[44] Nadler, D.A., Gerstein, M.S., Shaw, R.B., "Organizational Architecture: Designs for Changing Organizations (1st ed.).” CA: Jossey-Bass (1992).

[45] Nonaka, I., Takeuchi, H., "The Knowledge-Creating Company: How Japanese Companies Create the Dynamics of Innovation." Oxford University Press, 1995.

[46] Obeidat, B.Y., Abdallah, A.B., Aqqad, N.O., Akhoershiedah, A.H.O., Maqableh, M., "The Effect of Intellectual Capital on Organizational Performance: the Mediating Role of Knowledge Sharing." Communications and Network, vol. 9, pp. 1-27, pp. 2017.

[47] Peltokorpi, V., "Performance-Related Reward Systems in Japan: Practices and Preferences in Nordic Subsidiaries." The Intl Journal of HRM, vol. 22, no.2, 2507-2521, 2011.

[48] Posthuma, R.A., Campion, M.C., Masimova, M., Campion, M.A., "A High Performance Work Practices Taxonomy: Integrating the Literature and Directing Future Research." Journal of Management, vol. 39, no. 5, pp. 1184-1220, 2013.

[49] Ringle, C.M., Wende, S., Becker, J.M., "Smart PLS-3." Hamburg, <www.smartpls.com>, Accessed Dec 26, 2018

[50] Robert, C., Probst, T.M., Martocchio, J.J., Drasgow, F., Lawler, J.J., "Empowerment and Continuous Improvement in the United States, Mexico, Poland, and India: Predicting Fit on the Basis of the Dimensions of Power-Distance and Individualism." Journal of Applied Psychology, vol. 85, pp. 643-658, 2000.

[51] Roos, J., Roos, G., Dragonetti, N.C. and Edvinsson, L., Intellectual Capital: Navigating in the New Business Landscape, NYU Press, 1998.

[52] Sajeva., Svetlana.., "Fostering Knowledge Sharing Through Intrinsic Reward. In: Proceedings of the European Conference on Knowledge Management." Kidmore End, vol 9, pp. 854-861, 2014.

[53] Schuler, R.S. and MacMillan, I.C., "Gaining Competitive Advantage Through Human Resource Management Practices." Human Resource Management, vol. 3, pp. 241-255, 1986.

[54] Sikora, D.M., Thompson, K.W., Russell, Z.A., Ferris, G.R., "Reimagining Overqualified Human Resources to Promote Organizational Effectiveness and Competitive Advantage." Journal of Organizational Effectiveness: People and Performance, vol. 3, no. 1, pp. 23-42, 2016. 
[55] Simone, K., Nils, S. and Lisa, H., "Shared Leadership." Journal of Applied Organizational Psychology, vol. 48, no. 3, pp. 235-238, 2017.

[56] Singh, K., "Impact of HR Practices on Perceived Firm Performance in India." Asia Pacific Journal of Human Resources, vol. 42, no. 3, pp. 301-317, 2004.

[57] Soo, C., Tian, A.W., Teo, S.T., Cordery, J., "Intellectual Capital-Enhancing HR, Absorptive Capacity, and Innovation." Human Resource Management, vol. 56, no. 3, pp. 431-454, 2017.

[58] Stewart, T.A., "Intellectual Capital: The New Wealth of Organizations." Doubleday, 1997.

[59] Subramaniam, M., Youndt, M.A., "The Influence of Intellectual Capital on the Types of Innovative Capabilities." Academy of Management Journal, vol. 48, no. 3, pp. 450-464, 2005.

[60] Takeuchi, R., Chen, G., Lepak, D.P., "Through the Looking Glass of a Social System: Cross-Level Effects of High Performance Work Systems on Employees' Attitudes." Personnel Psychology, vol. 62, pp. 1-29, 2009.

[61] Tregaskis, O., Daniels, K., Glover, L., Butler, P., Meyer, M., "High Performance Work Practices and Firm Performance: A Longitudinal Case Study." British Journal of Management, vol. 24, pp. 225-244, 2013.

[62] Tyagi, S., Agrawal, S., Yang, K., Ying, H., “An Extended Fuzzy-AHP Approach to Rank the Influences of Socialization-Externalization-CombinationInternalization Modes on the Development Phase. Applied Soft Computing, vol. 52, pp. 505-518, 2017.

[63] Wanga, S., Yib, X., Lawlerc, J., Zhangd, M., "Efficacy of high-Performance Work Practices in Chinese Companies." The International Journal of HRM, vol. 22, no. 11, pp. 2419-2441, 2011.

[64] Welch, D. E., Welch, L.S., "The Importance of Language in International Knowledge Transfer Management." International Review, vol. 48, no. 3, pp. 339-360, 2008.

[65] Wood, S., "High Commitment Management and Pay Systems." Journal of Management Studies, vol. 33, no. 1, 53-77, 1996.

[66] Wright, P.M., McMahan, G.C., "Theoretical Perspectives for Strategic Human Resource Management." Journal of Management, vol. 18, no. 2, pp. 295-320, 1992.

[67] Wu, L., Wei, L., Zhang, Y., Han, T., "Employee Experienced HPWPs and Job Performance: Roles of Person-Job Fit and Intrinsic Motivation," Business Research, vol. 5, no. 3, pp. 344-363, 2011.

[68] Youndt, M. A., Snell, S.A., "Human Capital Configurations, Intellectual Capital, and Organizational Performance." Journal of Managerial Issues, vol. 16, no. 3), pp. 337-360, 2004.

[69] Zacharatos, A., Barling, J., Iverson, R., "HighPerformance Work Systems and Occupational Safety." Journal of Applied Psychology, vol. 90, no. 1, pp. 77-93, 2005.
[70] Özçelika, G., Aybasb, M., Uyargilc, C., "High Performance Work Systems and Organizational Values: Resource-based View Considerations." In: Proceedings of the 12th International Strategic Management Conference (ISMC), 28-30 October 2016, Antalya, Turkey.

[71] Thomas, R.M. Blending qualitative and quantitative research methods in theses and dissertations. California: Corwin Press, 2003

[72] Venkatesh, V., Brown, S.A. \& Balla, H., "Bridging the qualitative-quantitative divide: guidelines for conducting mixed methods research in information systems." MIS Quarterly, vol. 10, no. 10, pp. 1-20, 2013

[73] Fareed, M., Noor, W.S.M, Isa, MFM, Shahzad, Laeeq, H., "The Role of Human Capital Development and High Performance Work System in Sustaining the Human Resource Professionals' Effectiveness: A Lesson from Pakistan's Telco Companies." International Journal of Economic Perspectives, vol. 10, no. 11, pp. 512-525. 2016.

[74] Løwendahl, B.R., Strategic Management of Professional Service Firms, Copenhagen Business School Press, 2005. 